\title{
Managing hypertension during the COVID-19 pandemic
}

\author{
Sunil K. Nadar $\mathbb{D}^{1} \cdot$ Muzahir H. Tayebjee ${ }^{2} \cdot$ Michael Stowasser $^{3} \cdot$ James Brian Byrd $^{4}$
}

Received: 29 April 2020 / Revised: 6 May 2020 / Accepted: 7 May 2020 / Published online: 14 May 2020

(c) Springer Nature Limited 2020

We are currently in the midst of a COVID-19 pandemic caused by the severe acute respiratory syndrome coronavirus 2 (SARS-CoV-2). The global shutdown, with more than a third of the world's population facing some form of lockdown or quarantine measures, is on an unprecedented scale and will no doubt be etched in history. At the time of writing, more than 2 million people have been diagnosed to have the infection, with more than 50,000 deaths worldwide. It is expected that an even larger number are asymptomatic or mildly symptomatic and undiagnosed.

During this time, while the world's focus is on the novel coronavirus, there is a danger that other illnesses might be overlooked. Members of the public are being urged not to attend emergency departments for non-urgent matters, with the dual intention of protecting healthcare workers whilst freeing resources to treat the COVID-19 patients. Indeed, hospitals have reported a decrease in the number of patients attending emergency departments with myocardial infarctions and cerebrovascular accidents [1,2]. It is likely that patients are concerned about contracting the virus while attending the hospital and are staying away, as there are reports of delayed presentation of patients with acute myocardial infarctions [3]. It is imperative that these other life-threatening conditions are not forgotten while we deal with the coronavirus.

In addition to the acute conditions, management of stable chronic illnesses such as hypertension and diabetes may also be affected. Many hospitals worldwide have cancelled

Sunil K. Nadar

sunilnadar@gmail.com

1 Department of Medicine, Sultan Qaboos University Hospital, Muscat, Oman

2 Department of Cardiology, Leeds teaching hospital, NHS trust, Leeds, UK

3 Endocrine Hypertension research center, University of Queensland, Princess Alexandra hospital, Brisbane, Australia

4 Department of Internal Medicine, University of Michigan Medical Schooll, Ann Arbor, MI, USA all in-person elective patient care, including routine outpatient clinics, and moved towards telemedicine as part of social distancing measures. Doing so also preserves resources to help tackle supply chain problems and other challenges created by a surge in patients infected by the novel coronavirus. Even in these circumstances, it is important that blood pressure and blood glucose levels are monitored regularly. This is particularly important as patients with diabetes and hypertension may be at higher risk for complications of COVID-19 [4].

Early data from China and the United States suggest that hypertension appears to be the most prevalent comorbidity among patients admitted with COVID-19 being present in at least $30-49 \%$ of them $[4,5]$. Hypertensive patients who develop COVID-19 are more likely to be admitted to hospital than normotensive individuals [6]. The presence of hypertension also seems to be associated with poorer outcomes from COVID-19 [7]. It not clear whether it is hypertension per se that contributes to the increased morbidity, or whether patients with hypertension have more underlying health problems, as data have confirmed that patients with multiple comorbidities are likely to fare worse [8]. We should bear in mind though, that these are retrospective data from patients admitted with COVID-19 and therefore can only suggest association and not causation. Nevertheless, the interaction of SARS-CoV-2 virus with ACE2 in the endothelial cell [9] does raise the possibility that endothelial dysfunction, which commonly occurs in hypertension [10], may exacerbate the effect of the virus.

A major problem during a pandemic with a hithertounknown organism is early conflicting data that can cause uncertainty and confusion in the management of these patients. It has been shown that SARS-CoV-2 binds to cells via the angiotensin converting enzyme (ACE) 2 receptor [9] thereby gaining entry to the cells. Concern was therefore raised at the start of the pandemic that ACE inhibitors and angiotensin receptor blockers (ARBs), medications that are commonly used for hypertension and heart failure, could have a potential deleterious effect [11], as ACE2 is widely expressed in the cardiovascular system and is up regulated 
by these drugs in some tissues in a subset of animal models $[12,13]$. These initial publications led to a considerable amount of discussion and debate with the counter argument being that ACE inhibitors and ARBs have been shown to protect from lung injury in experimental models of coronavirus infections [14]. These agents have also previously been demonstrated to reduce systemic inflammation and could potentially reduce the degree of multi-organ failure seen in severe COVID-19 [15]. It was also considered that uncontrolled blood pressure or heart failure that could ensue as a result of discontinuation of these therapies and could contribute to morbidity in infected patients. Guidance was promptly issued advising that these drugs not be discontinued [16, 17]. Subsequent data have raised the possibility that patients treated with ACE inhibitors or ARBs do indeed have a better outcome, with the crucial caveat that the possibility of unmeasured confounding and bias precludes drawing cause-effect conclusions from the clinical studies available thus far. A recent retrospective study from China comparing outcomes on hospitalised patients with COVID-19 with and without ACE inhibitors or ARBs for hypertension has suggested that in the former all-cause mortality was lower (adjusted HR, 0.42; 95\% CI, $0.19-0.92 ; P=0.03$ ) [18]. Another retrospective study from China showed that fewer patients on ACE inhibitors or ARBs had severe disease as compared with those who were not on these drugs $(23.5 \%$ and $48 \%$, respectively). The ACE inhibitor/ARB-treated group also had significantly higher $\mathrm{CD} 3+$ and $\mathrm{CD} 8+\mathrm{T}$ cells and a trend towards lower IL-6 levels [19] More recent analyses (preprints), though, have suggested that after adjustment for certain likely confounders, the signal for improved outcomes is no longer as strong as first believed [20]. In the end, the effects of treatment with ACE inhibitors or ARBs will only be positively identified through RCTs, which are ongoing [21].

There is also mounting concern about possible thromboembolic complications of the virus and a possible procoagulable state [22]. Various factors which can lead to a hypercoagulable state such as inflammation, hypoxia, immobilisation, dehydration and diffuse intravascular coagulation have been described in COVID-19. In addition, hypertension has also known to be associated with a hypercoagulable state [23] and it is possible that an interaction between these two conditions might lead to a worsening thrombotic milieu.

We are still learning more about this new virus and information continues to mount. In the meantime, it would be prudent to continue the guideline-based management of all chronic conditions and cardiovascular risk factors such as diabetes and hypertension. Healthcare practitioners need to ensure that patients are appropriately advised and have access to their drugs. Patients should be made aware that despite the lockdown, pharmacies and hospitals are still open. Indeed the British heart foundation has recently issued a notice reminding the public not to ignore chest pain and seek help immediately, as they also report a 50\% drop in patients presenting with a myocardial infarction since the start of the pandemic [22]. General practitioners and family physicians are still available for consultations, even if it is over the telephone. Patients should also be encouraged to monitor their blood pressure at home, be adherent with treatment, and adopt healthy lifestyles. In many countries, individuals are allowed to go out to exercise, while ensuring they maintain social distancing and take all the other necessary precautions as advised by their public health authorities.

This current pandemic has brought about profound changes in the social and economic lives of many. It has also changed the way healthcare is being delivered and prioritised. Even when social restrictions are relaxed, it is hard to imagine that things would quickly (if ever) go back to how they were before the pandemic. Whilst we get used to the new "normal" way of life, we should remember that other diseases and illness are still out there and still need our care. Perhaps this is a time for much of the control of chronic illnesses to go back to the community and the patients. We have to ensure that patients with chronic illnesses are not forgotten in our fight against SARS-CoV-2 and do not end up as collateral damage.

\section{Compliance with ethical standards}

Conflict of interest The authors declare that they have no conflict of interest.

Publisher's note Springer Nature remains neutral with regard to jurisdictional claims in published maps and institutional affiliations.

\section{References}

1. Garcia S, Albaghdadi MS, Meraj PM, Schmidt C, Garberich R, Jaffer FA, et al. Reduction in ST-segment elevation cardiac catheterization laboratory activations in the United States during COVID-19 Pandemic. J Am Coll Cardiol. 2020. https://doi.org/ 10.1016/j.jacc.2020.04.011. [Epub ahead of print]

2. Morelli N, Rota E, Terracciano C, Immovilli P, Spallazzi M, Colombi D, et al. The Baffling Case of Ischemic Stroke Disappearance from the Casualty Department in the COVID-19 Era. Eur Neurol. 2020;14:1-3.

3. Tam CF, Cheung KS, Lam S, Wong A, Yung A, Sze M, et al. Impact of Coronavirus Disease 2019 (COVID-19) Outbreak on ST-Segment-Elevation Myocardial Infarction Care in Hong Kong, China. Circ Cardiovasc Qual Outcomes. 2020;13:e006631.

4. Richardson S, Hirsch JS, Narasimhan M, Crawford JM, McGinn $\mathrm{T}$, Davidson KW, et al. Presenting characteristics, comorbidities, and outcomes among 5700 patients hospitalized with COVID-19 in the New York City area. JAMA. 2020. https://doi.org/10.1001/ jama.2020.6775 
5. Zheng Z, Peng F, Xu B, Zhao J, Liu H, Peng J, et al. Risk factors of critical \& mortal COVID-19 cases: a systematic literature review and meta-analysis. J Infect. 2020. https://doi.org/10.1016/j. jinf.2020.04.021

6. Garg S, Kim L, Whitaker M, O'Halloran A, Cummings C, Holstein $\mathrm{R}$, et al. Hospitalization rates and characteristics of patients hospitalized with laboratory-confirmed coronavirus disease 2 . MMWR Morb Mortal Wkly Rep. 2020;69:458-64.

7. Li X, Xu S, Yu M, Wang K, Tao Y, Zhou Y, et al. Risk factors for severity and mortality in adult COVID-19 inpatients in Wuhan. J Allergy Clin Immunol. 2020. https://doi.org/10.1016/j.jaci.2020. 04.006. [Epub ahead of print]

8. Yao Q, Wang P, Wang X, Qie G, Meng M, Tong X, et al. Retrospective study of risk factors for severe SARS-Cov-2 infections in hospitalized adult patients. Pol Arch Intern Med. 2020. https:// doi.org/10.20452/pamw.15312. [Epub ahead of print]

9. Hoffmann M, Kleine-Weber H, Schroeder S, Kruger N, Herrler T, Erichsen S, et al. SARS-CoV-2 cell entry depends on ACE2 and TMPRSS 2 and is blocked by a clinically proven protease inhibitor. Cell. 2020;181:271-80.

10. Nadar S, Blann AD, Lip GY. Endothelial dysfunction: methods of assessment and application to hypertension. Curr Pharm Des. 2004;10:3591-605.

11. Fang L, Karakiulakis G, Roth M. Are patients with hypertension and diabetes mellitus at increased risk for COVID-19 infection? Lancet Respir Med. 2020;8:e21.

12. Li XC, Zhang J, Zhuo JL. The vasoprotective axes of the reninangiotensin system: physiological relevance and therapeutic implications in cardiovascular, hypertensive and kidney diseases. Pharm Res. 2017;125:21-38.

13. Brojakowska A, Narula J, Shimony R, Bander J. Clinical implications of SARS-Cov2 interaction with renin angiotensin system. J Am Coll Cardiol. 2020. https://doi.org/10.1016/j.jacc.2020.04. 028 .
14. Kuba K, Imai Y, Rao S, Gao H, Guo F, Guan B, et al. A crucial role of angiotensin converting enzyme 2 (ACE2) in SARS coronavirus-induced lung injury. Nat Med. 2005;11:875-9.

15. Di RD, Tuttolomondo A, Butta C, Miceli S, Licata G, Pinto A. Effects of ACE-inhibitors and angiotensin receptor blockers on inflammation. Curr Pharm Des. 2012;18:4385-413.

16. European society of Hypertension statement. 2020. www. eshonline.org/spotlights/esh-statement-on-covid-19/ Accessed 28 Apr 2020

17. American College of Cardiology, American heart association, Heart failure society of America joint statement. 2020 https://www.acc.org/latest-in-cardiology/articles/2020/03/17/08/ 59/hfsa-acc-aha-statement-addresses-concerns-re-using-raas-anta gonists-in-covid-19 Accessed 28 Apr 2020

18. Zhang P, Zhu L, Cai J, Lei F, Qin JJ, Xie J, et al. Association of inpatient use of angiotensin converting enzyme inhibitors and angiotensin ii receptor blockers with mortality among patients with hypertension hospitalized with COVID-19. Circ Res. 2020. https://doi.org/10.1161/CIRCRESAHA.120.317134.

19. Meng J, Xiao G, Zhang J, He X, Ou M, Bi J, et al. Reninangiotensin system inhibitors improve the clinical outcomes of COVID-19 patients with hypertension. Emerg Microbes Infect. 2020;9:757-60.

20. Preprint at http://www.nephjc.com/news/covidace2 Accessed 28 Apr 2020.

21. Clinical trials 2020. https://clinicaltrials.gov/ct2/show/ NCT04338009 Accessed 28 April 2020

22. Klok FA, Kruip MJHA, van der Meer NJM, Arbous MS, Gommers DAMP, Kant KM, et al. Incidence of thrombotic complications in critically ill ICU patients with COVID-19. Thromb Res. 2020. https://doi.org/10.1016/j.thromres.2020.04.013. [Epub ahead of print].

23. Nadar S, Lip GY. Hypertension and the prothrombotic state. J Am Coll Cardiol. 2003;41:1847. 